University of Nebraska - Lincoln

DigitalCommons@University of Nebraska - Lincoln

$2-2010$

\title{
Application of the Priestley-Taylor Approach in a Two-Source Surface Energy Balance Model
}

\author{
Nurit Agam \\ USDA-ARS, nurit.agam@gmail.com \\ William P. Kustas \\ USDA-ARS \\ Martha C. Anderson \\ USDA-ARS, martha.anderson@ars.usda.gov \\ John M. Norman \\ University of Wisconsin-Madison \\ Paul D. Colaizzi \\ USDA-ARS, Paul.Colaizzi@ARS.USDA.GOV
}

See next page for additional authors

Follow this and additional works at: https://digitalcommons.unl.edu/usdaarsfacpub

Agam, Nurit; Kustas, William P.; Anderson, Martha C.; Norman, John M.; Colaizzi, Paul D.; Howell, Terry A.; Prueger, John H.; Meyers, Tilden P.; and Wilson, Tim B., "Application of the Priestley-Taylor Approach in a Two-Source Surface Energy Balance Model" (2010). Publications from USDA-ARS / UNL Faculty. 1834. https://digitalcommons.unl.edu/usdaarsfacpub/1834

This Article is brought to you for free and open access by the U.S. Department of Agriculture: Agricultural Research Service, Lincoln, Nebraska at DigitalCommons@University of Nebraska - Lincoln. It has been accepted for inclusion in Publications from USDA-ARS / UNL Faculty by an authorized administrator of DigitalCommons@University of Nebraska - Lincoln. 


\section{Authors}

Nurit Agam, William P. Kustas, Martha C. Anderson, John M. Norman, Paul D. Colaizzi, Terry A. Howell, John H. Prueger, Tilden P. Meyers, and Tim B. Wilson 


\title{
Application of the Priestley-Taylor Approach in a Two-Source Surface Energy Balance Model
}

\author{
Nurit Agam,* William P. Kustas, And Martha C. Anderson \\ Hydrology and Remote Sensing Laboratory, Agricultural Research Service, USDA, Beltsville, Maryland \\ JOHN M. NORMAN \\ Department of Soil Science, University of Wisconsin-Madison, Madison, Wisconsin \\ Paul D. Colaizzi And Terry A. Howell \\ Conservation and Production Research Laboratory, Agricultural Research Service, USDA, Bushland, Texas \\ JOHN H. PRUEGER \\ National Soil Tilth Laboratory, Agricultural Research Service, USDA, Ames, Iowa \\ Tilden P. MEYers AND TIM B. Wilson \\ NOAA/Atmospheric Turbulence and Diffusion Division, Oak Ridge, Tennessee
}

(Manuscript received 5 November 2008, in final form 6 July 2009)

\begin{abstract}
The Priestley-Taylor (PT) approximation for computing evapotranspiration was initially developed for conditions of a horizontally uniform saturated surface sufficiently extended to obviate any significant advection of energy. Nevertheless, the PT approach has been effectively implemented within the framework of a thermal-based two-source model (TSM) of the surface energy balance, yielding reasonable latent heat flux estimates over a range in vegetative cover and climate conditions. In the TSM, however, the PT approach is applied only to the canopy component of the latent heat flux, which may behave more conservatively than the bulk (soil + canopy) system. The objective of this research is to investigate the response of the canopy and bulk PT parameters to varying leaf area index (LAI) and vapor pressure deficit (VPD) in both natural and agricultural vegetated systems, to better understand the utility and limitations of this approximation within the context of the TSM. Micrometeorological flux measurements collected at multiple sites under a wide range of atmospheric conditions were used to implement an optimization scheme, assessing the value of the PT parameter for best performance of the TSM. Overall, the findings suggest that within the context of the TSM, the optimal canopy PT coefficient for agricultural crops appears to have a fairly conservative value of $\sim 1.2$ except when under very high vapor pressure deficit (VPD) conditions, when its value increases. For natural vegetation (primarily grasslands), the optimal canopy PT coefficient assumed lower values on average $(\sim 0.9)$ and dropped even further at high values of VPD. This analysis provides some insight as to why the PT approach, initially developed for regional estimates of potential evapotranspiration, can be used successfully in the TSM scheme to yield reliable heat flux estimates over a variety of land cover types.
\end{abstract}

* Current affiliation: Gilat Research Center, Agricultural Research Organization of Israel, D. N. Negev, Israel.

Corresponding author address: Nurit Agam, Gilat Research Center, Agricultural Research Organization of Israel, D. N. Negev 85280, Israel.

E-mail: nurit.agam@gmail.com

DOI: 10.1175/2009JHM1124.1

(C) 2010 American Meteorological Society

\section{Introduction}

The two-source model (TSM) of Norman et al. (1995) is a land surface parameterization of the radiative and turbulent energy exchanges between the soil, vegetation, and lower atmosphere in which radiometric land surface temperature, derived from remote sensing images collected in the thermal wave band, serves as the 


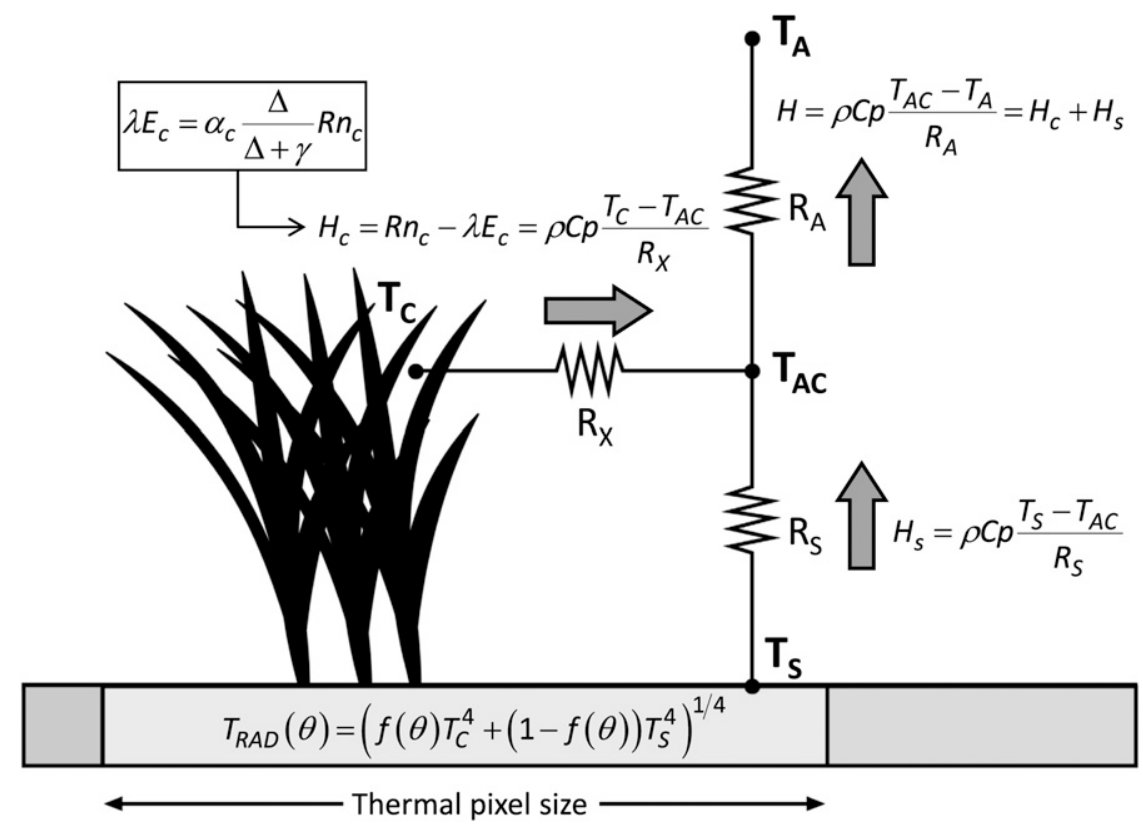

FIG. 1. Schematic diagram representing the TSM resistance formulation used in computing sensible heat flux. The model computes fluxes of $H$ from the soil and canopy (subscripts $s$ and $c$ ) along gradients in $T$, derived from the directional $T_{\mathrm{RAD}}(\theta)$, given $f(\theta)$. The fluxes are regulated by transport resistances $R_{A}$ (aerodynamic), $R_{x}$ (bulk leaf boundary layer), and $R_{S}$ (soil surface boundary layer). Here, $\lambda E_{C}$ is computed by the PT approach [Eq. (3)], and by residual, $H_{c}=$ $\mathrm{Rn}_{c}-\lambda E_{c}$, which is used to obtain initial estimates of component temperatures $\left(T_{c}\right.$ and $\left.T_{s}\right)$, heat fluxes $\left(H_{c}\right.$ and $\left.H_{s}\right)$ and the temperature in the canopy air space $\left(T_{\mathrm{AC}}\right)$. The value of $\lambda E_{s}$ is solved by residual in the energy balance for the soil [see Eq. (1)].

key boundary condition. The TSM formulation is based on the two-source energy balance equation of

$$
\mathrm{Rn}_{c}+\mathrm{Rn}_{s}+G+H_{c}+H_{s}+\lambda E_{c}+\lambda E_{s}=0,
$$

where the subscripts $c$ and $s$ denote the canopy and soil components, respectively; $\mathrm{Rn}$ is net radiation; $G$ is soil heat flux; and $H$ and $\lambda E$ are sensible and latent heat fluxes, respectively. This modeling framework follows earlier development of two-source schemes based on the Penman-Monteith big-leaf model (Monteith 1981) to deal with sparse canopy cover conditions (Shuttleworth and Wallace 1985; Shuttleworth and Gurney 1990). Given an estimate of fractional vegetation cover, the TSM partitions the observed surface temperature into soil and canopy contributions (illustrated in Fig. 1):

$$
T_{\mathrm{RAD}}(\theta)=\left\{f(\theta) T_{C}^{4}+[1-f(\theta)] T_{S}^{4}\right\}^{1 / 4},
$$

where $T_{\mathrm{RAD}}(\theta)$ is the surface radiometric temperature at look angle $\theta, f(\theta)$ is fractional vegetation cover seen by the sensor, and $T_{C}$ and $T_{S}$ are the derived canopy and soil temperatures, respectively. The component (soil and vegetation) sensible heat fluxes $\left(H_{S}\right.$ and $\left.H_{C}\right)$ are then computed along the gradients in temperature, regulated by transport resistances (see Fig. 1). Extinction of net radiation within the canopy $\left(\mathrm{Rn}_{c}\right)$ is approximated with an analytical formalism described by Campbell and Norman (1998), based primarily on leaf absorptivity and leaf area index (LAI), whereas $G$ is parameterized as a fraction (0.31) of the net radiation above the soil surface $\left(\mathrm{Rn}_{S}\right)$, following Choudhury et al. (1994). The canopy transpiration component of the latent heat flux $\lambda E_{C}$ is approximated using the PriestleyTaylor approach:

$$
\lambda E_{c}=\alpha_{c} \frac{\Delta}{\Delta+\gamma} \mathrm{Rn}_{c},
$$

where $\alpha_{c}$ is the PT parameter applied to the canopy (details provided later), $\Delta$ is the slope of saturation vapor pressure versus temperature, and $\gamma$ is the psychrometric constant. Lastly, the soil evaporation term is computed as the residual of the overall energy balance equation [Eq. (1)].

The use of the PT approach within the TSM scheme to estimate canopy transpiration was motivated by its simplicity and the apparent robustness of its predictions. It provides information required to efficiently solve the 
system of equations defining the component soil and canopy heat fluxes and temperatures, which are critical to constraining fluxes from the two-source system. If these component temperatures are known a priori-for example, through direct measurements (impractical over wide spatial and temporal scales) or through dualangle thermal infrared decomposition (e.g., Otterman et al. 1992; François 2002) - then the soil and canopy latent heat fluxes can be computed directly as a residual to the component energy budgets, eliminating the need for the PT approximation (Sanchez et al. 2008). However, if only the composite temperature is available (which is generally the case), then some initial assumption about either soil or canopy evaporation must be made to inform the partitioning of temperatures and heat fluxes between these two sources.

The performance of the TSM has been tested in both modes, that of using the PT approach and using observations of component temperatures derived from detailed infrared thermometer (IRT) observations (Kustas and Norman 1999; Sanchez et al. 2008) and from dualangle measurements (Kustas and Norman 1997). In these tests, model fluxes from the PT mode provided similar or better agreement with observations than did model fluxes using observed values of $T_{S}$ and $T_{C}$. The generally better performance using the $\mathrm{PT}$ approach was most pronounced in cases in which dual-angle measurements were employed to derive $T_{S}$ and $T_{C}$, which often has much greater uncertainty in estimating reliable component temperatures. Within the context of the TSM, the PT mode appears to be a simple and economical approach, and it provides robust assessments of component and system evaporative fluxes over a wide range of vegetation cover and climatic conditions (e.g., Kustas and Norman 1999, 2000a,b; French et al. 2003, 2005; Li et al. 2006).

Still, legitimate questions can be raised regarding the validity of implementing the PT approximation in the TSM, as a parameterization for the canopy transpiration flux component (e.g., Sanchez et al. 2008). Studies have indicated that the PT coefficient associated with the combined soil-plant-atmosphere system is not constant, but it does show dependency on LAI, vapor pressure deficit (VPD), and soil moisture (e.g., Jury and Tanner 1976; Flint and Childs 1991; Pereira 2004; Diaz-Espejo et al. 2005; Baldocchi and Xu 2007). The TSM, however, applies the PT approach only to the canopy component of the latent heat flux, which may behave more conservatively than that associated with the bulk system. The objective of this research was to investigate the behavior of the canopy PT parameter diagnosed by the TSM, and its utility and limitations over a range in vegetation cover and moisture conditions.

\section{Scientific background}

\section{a. Priestley-Taylor approach applied to the bulk system}

The Priestley and Taylor (1972) approach is a simplification of Penman's formulation of evapotranspiration ET (Penman 1948), assuming that the equilibrium term $\lambda E_{\text {eq }}$ (Slatyer and McIlroy 1961) is significantly larger than the aerodynamic term $\lambda E_{a}$. On the basis of this assumption, the Priestley-Taylor formulation for ET is expressed as

$$
\lambda E=\alpha \lambda E_{\mathrm{eq}},
$$

where $\alpha$ is the so-called Priestley-Taylor coefficient.

Numerous studies have found that the value of $\alpha$ can be quite variable (e.g., Jury and Tanner 1976; Flint and Childs 1991; Castellvi et al. 2001; Pereira 2004; Diaz-Espejo et al. 2005; Baldocchi and Xu 2007). When the soil has ample water, the latent heat flux is determined by the atmospheric evaporative demand, and $\alpha$ increases with increasing $\lambda E_{a} / \lambda E$ - that is, under conditions of strong horizontal advection of sensible heat flux (Priestley and Taylor 1972; Jury and Tanner 1975; Tanner and Jury 1976). This has been experimentally documented by Singh and Taillefer (1986), Diaz-Espejo et al. (2005), and $\mathrm{Li}$ and $\mathrm{Yu}$ (2007). Once soil moisture decreases, and the soil and/or vegetation can no longer transpire at the potential rate, the surface resistance to $\lambda E$ increases and $\alpha$ decreases (e.g., De Bruin 1983; Flint and Childs 1991; Raupach 2000).

Each of the previously mentioned studies treated the soil-biosphere-atmosphere as a bulk system, based on the big-leaf assumption, which may be reasonable for dense vegetation, but is less appropriate for partial canopies. Soil evaporation becomes rapidly limited by the soil hydraulic conductivity when the water content of the surface layer $(\sim 0-5 \mathrm{~cm})$ drops below a certain threshold, whereas transpiration continues at an energylimited rate until the moisture content over a large part of the root zone drops below a critical level (Tanner and Jury 1976). For vegetated surfaces, $50 \%-80 \%$ of the available soil water in the plant root zone can be extracted at the potential rate. For bare soil, however, potential evaporation is limited to only $\sim 40 \%$ of the available soil water in the near-surface $(0-5 \mathrm{~cm})$ layer (Flint and Childs 1991). With $\alpha$ for the bulk system effectively representing a combination of soil evaporation and canopy transpiration, only under the wettest soil moisture conditions can $\alpha$ be expected to remain at $\sim 1.26$ for partial canopy cover conditions. At low vegetation cover fraction (or LAI), it is more likely that $\alpha$ will be less than 1.26 , because the soil evaporation 
component of ET rapidly decreases as the soil surface dries out (Stannard 1993). Conversely, $\alpha$ has been reported to exceed 1.26 and reach values of $\sim 2$, particularly under well-watered closed-canopy conditions (e.g., Baldocchi 1994; Baldocchi et al. 1997).

There are both theoretical and experimental studies indicating that the value of $\alpha$ varies significantly with LAI, VPD, and soil moisture (e.g., Jury and Tanner 1976; Flint and Childs 1991; Baldocchi 1994; Baldocchi et al. 1997; Pereira 2004; Diaz-Espejo et al. 2005; Baldocchi and Xu 2007). However, a recent study by Pereira et al. (2007) used the Priestley-Taylor approach only for the canopy elements (with the traditional value of $\alpha_{c}=1.26$ ) for estimating transpiration from well-watered isolated fruit trees and obtained excellent agreement with sapflow measurements over a wide range of LAI. This implies that applying the Priestley-Taylor method to the canopy component may result in a coefficient that is more conservative than $\alpha$ for the whole (bulk) soilbiosphere-atmosphere system $\alpha_{\text {bulk }}$ when the canopy is unstressed. This study investigates the behavior of the value of $\alpha$ when applied to solely the vegetation component $\alpha_{c}$, compared to $\alpha_{\text {bulk. }}$.

\section{b. Two-source formulations for $\alpha$}

\section{1) TANNER AND JURY}

One of the first attempts to account for the effects of vegetation amount on evaporation from the bulk system by separating evaporation and transpiration components was formulated by Ritchie (1972). Tanner and Jury (1976) adapted Ritchie's methodology by applying the Priestley-Taylor approach for the soil and vegetated canopy components. They assumed that under energy-limited conditions (i.e., ample soil water), the soil evaporation $\lambda E_{s}$ and transpiration $\lambda E_{c}$ can be expressed as

$$
\begin{aligned}
& \lambda E_{s}=\alpha_{s} \tau \lambda E_{\mathrm{eq}} \quad \text { and } \\
& \lambda E_{c}=\alpha_{c}(1-\tau) \lambda E_{\mathrm{eq}},
\end{aligned}
$$

where $\tau$, a canopy transmission factor representing the ratio of net all-wave radiation at the soil surface $\left(\mathrm{Rn}_{s}\right)$ to that above the canopy $(\mathrm{Rn})$, is given by

$$
\tau=\frac{\mathrm{Rn}_{s}}{\mathrm{Rn}} \approx \exp (-\beta \mathrm{LAI}) .
$$

In Eqs. (5) and (6), $\beta$ is a semiempirical coefficient dependent on leaf angle distribution and soil and canopy temperatures (Kustas and Norman 1999), and $\alpha_{s}$ and $\alpha_{c}$ are modified PT coefficients applied to $\lambda E_{s}$ and $\lambda E_{c}$, respectively, and are given by

$$
\begin{aligned}
& \alpha_{s}=\left\{\begin{array}{ll}
1 & \left(\text { for } \tau \leq \tau_{0}\right) \\
\alpha-\frac{(\alpha-1)(1-\tau)}{\left(1-\tau_{0}\right)} & \left(\text { for } \tau>\tau_{0}\right)
\end{array}\right. \text { and } \\
& \alpha_{c}=\frac{\left(\alpha-\alpha_{s} \tau\right)}{(1-\tau)},
\end{aligned}
$$

where $\alpha=1.26$ for energy limited (wet) conditions with a full canopy cover, $\tau_{0}$ is a critical value of $\tau$ below which the canopy is sufficiently closed that soil evaporation approaches equilibrium ( $\alpha_{s} \approx 1$ for wet soil conditions). Equation (7) is applied under energy-limited conditions. The choice of $\tau_{0}$ may vary between 0.2 and 0.5 , and its exact value was found not to be crucial (Tanner and Jury 1976). This approach was recently applied to cornfields in Wisconsin (Morgan et al. 2003) and soybeans in Iowa (Sauer et al. 2007).

\section{2) STANNARD}

Stannard (1993) suggested that for estimating $\lambda E$ at the soil-biosphere-atmosphere level, the "system" or "bulk" $\alpha$ should be modified to account for separate contributions from the canopy and soil:

$$
\begin{aligned}
\alpha_{\text {bulk }}= & \alpha-C_{8} \exp (-\mathrm{LAI})+C_{8} \exp (-\mathrm{LAI}) \\
& \times \exp \left(-C_{9} \int_{0}^{t} E_{s} d \widehat{t}\right),
\end{aligned}
$$

where $\alpha=1.26, C_{8}$ and $C_{9}$ are parameters determined using nonlinear regression, and $\int_{0}^{t} E_{s} d t$ is the amount of water evaporated since the last rainfall. For details about the individual terms in Eq. (8), see Stannard (1993). In this formulation, either a large LAI, or a recent rainfall, are sufficient to drive $\alpha_{\text {bulk }}$ toward its maximum value of 1.26 , whereas either a small LAI or an extended dry spell results in a minimum value of $\alpha_{\text {bulk }}=\left(\alpha-C_{8}\right) \approx 0.35$. Note that in determining values of $C_{8}$ and $C_{9}$, Stannard (1993) used data from a sparsely vegetated site with a sandy soil overlying a shallow water table (0.8-1.6-m depth). Therefore, although the soil surface may have dried out in the absence of precipitation, the vegetation had ample moisture at all times.

\section{3) THE TWO-SOURCE MODEL}

Detailed descriptions of the principles and formulation of the two-source energy balance model are given by Norman et al. (1995) and Kustas and Norman (1999, 2000a). In the model, the transpiration component of the latent heat flux is approximated using the PriestleyTaylor equation [Eq. (3)], in which $\mathrm{Rn}_{c}$ is the amount of net radiation intercepted by the canopy, given in the original form of the TSM (Norman et al. 1995) as 


$$
\mathrm{Rn}_{c}=\operatorname{Rn}[1-\exp (-\beta \mathrm{LAI})]
$$

Given an initial estimate of $\lambda E_{c}$ using $\alpha_{c}=1.26$ (assuming potential or unstressed transpiration), the TSM computes $\lambda E_{s}$ as the residual of the overall energy balance. If $\lambda E_{s}$ is found to be less than 0 , suggesting condensation of water vapor onto the soil, which is unlikely to occur during daytime dry convective conditions, then an additional iterative stage is executed, during which $\alpha_{c}$ is gradually reduced until $\lambda E_{s} \geq 0$, reflecting some degree of canopy stress.

Although current versions of the TSM use a more physically based scheme for partitioning net radiation, accounting for differences in longwave and shortwave radiation attenuation in the canopy layer (Kustas and Norman 2000a), the simplified form in Eq. (10) has been used in this study to develop a conceptual/analytical relationship between $\alpha_{\text {bulk }}$ and $\alpha_{s}$ and $\alpha_{c}$. For this reason, $\lambda E_{s}$ is also expressed here in terms of the PriestleyTaylor equation

$$
\lambda E_{s}=\alpha_{s} \frac{\Delta}{\Delta+\gamma}\left(\mathrm{Rn}_{s}+G\right),
$$

where $G$ is estimated as a fraction of $\mathrm{Rn}_{s}$, that is, $G=$ $c \mathrm{Rn}_{s}=c \mathrm{Rn} \exp (-\beta \mathrm{LAI})$. Note that this differs from the TSM algorithm, which solves for $\lambda E_{s}$ as a residual from the soil surface energy balance equation, thus not requiring an estimate of $\alpha_{s}$ for the model operation.

The original Priestley-Taylor expression for the total $\lambda E$ is

$$
\lambda E=\alpha_{\text {bulk }} \frac{\Delta}{\Delta+\gamma}(\mathrm{Rn}-G) .
$$

However, $\lambda E$ can also be expressed as the sum of the $\lambda E_{c}$ and $\lambda E_{s}$ as follows:

$$
\begin{aligned}
\lambda E= & \frac{\Delta}{\Delta+\gamma} \operatorname{Rn}\left[\alpha_{c}-\alpha_{c} \exp (-\beta \mathrm{LAI})+\alpha_{s}(1-c)\right. \\
& \times \exp (-\beta \mathrm{LAI})] .
\end{aligned}
$$

A conceptual formulation of $\alpha_{\text {bulk }}$ can therefore be derived from Eqs. (12) and (13):

$$
\alpha_{\text {bulk }}=\frac{\alpha_{c}-\alpha_{c} \exp (-\beta \mathrm{LAI})+\alpha_{s}(1-c) \exp (-\beta \mathrm{LAI})}{1-c \exp (-\beta \mathrm{LAI})} .
$$

As in Stannard's formulation, the dependency of $\alpha_{\text {bulk }}$ on LAI in Eq. (14) is explicit.

Note that although the TSM has some ability to adjust $\alpha_{c}$ in response to perceived canopy stress, it is unlikely that this adjustment will result in the "optimal" or the most appropriate $\alpha_{c}$ value in every case for the following reasons: 1) the model has an iterative mechanism to reduce $\alpha_{c}$ but not to increase it, which may be required under strong advective conditions; 2) some degree of canopy stress $\left(\alpha_{c}<1.26\right)$ could be realized before soil evaporation goes to zero $\left(\lambda E_{s}>0\right)$, but there is no mechanism in the model to capture this condition.

\section{Methodology}

\section{a. Data description}

Micrometeorological measurements collected at multiple sites under a wide range of atmospheric conditions were used in this study. Data from agricultural fields were collected in Maryland [Optimizing Production Inputs for Economic and Environmental Enhancement (OPE3)], Iowa [Soil Moisture Experiment 2002 (SMEX02)], Texas (Bushland) and Arizona (Maricopa), representing gradually changing climatic zones from the temperate climate in Maryland to the Sonoran Desert in Arizona. The crops grown at these sites were corn, soybean, alfalfa, sorghum, wheat, and cotton. Data were also collected at rangeland sites (both grassland and shrubland) in Oklahoma [Southern Great Plains 1997 (SGP97)], Arizona [Audubon, Monsoon '90, and Soil Moisture Experiment 2004 (SMEX04)], Mississippi (Goodwin Creek), and Montana (Fort Peck). The exact location of the sites, the dates of data collection, and mean LAI and VPD at each site are listed in Table 1; a further description of the site conditions and instrumentation configurations can be found in the references listed in Table 1.

The sensible and latent heat fluxes were measured using several micrometeorological techniques. In Maricopa, both Bowen ratio and eddy covariance (EC) methods were used (Kustas et al. 1989; Kustas 1990). In Bushland, $\lambda E$ was measured by large weighing lysimeters (Howell et al. 1995a), and $H$ was determined as the residual in the energy balance equation. In Monsoon '90, both EC and flux variance approaches were used (Kustas and Goodrich 1994; Stannard et al. 1994). For all other sites, $H$ and $\lambda E$ were measured only using the EC method. For comparison with fluxes computed by the TSM (which assumes closure of the energy budget), a closure correction was applied to all EC flux datasets by assigning the residual flux to $\lambda E$ (the residual method; $\mathrm{Li}$ et al. 2005). At all sites, measurements of net radiation, soil heat flux, and radiometric surface temperature were also collected, along with meteorological data (e.g., air temperature, VPD, and wind speed).

At these sites, LAI was measured using several different methods. In OPE3 (Sanchez et al. 2008), SMEX04 
TABLE 1. General information of the various datasets analyzed in the study. This includes vegetation/crop type, geographic location, year and length of record of the observations, mean and STD of LAI and VPD, and citations that provide detailed information of sites and data. WC refers to Walnut Creek, near Ames, IA. ER refers to El Reno, OK.

\begin{tabular}{|c|c|c|c|c|c|c|c|c|}
\hline Dataset & $\begin{array}{c}\text { Vegetation/crop } \\
\text { type }\end{array}$ & Latitude & Longitude & Year & Day of year & $\begin{array}{l}\text { LAI mean } \\
\qquad(\mathrm{STD})\end{array}$ & $\begin{array}{l}\text { VPD mean } \\
\quad(\mathrm{STD})\end{array}$ & $\begin{array}{l}\text { Complete } \\
\text { description }\end{array}$ \\
\hline \multicolumn{9}{|l|}{ Agricultural fields } \\
\hline OPE3 & Corn & 39.01667 & -76.86667 & 2004 & $161-210$ & $\begin{array}{l}1.56 \\
(0.77)\end{array}$ & $\begin{array}{l}1.56 \\
(0.55)\end{array}$ & Sanchez et al. (2008) \\
\hline SMEX02 & & & & 2002 & $171-190$ & & & Kustas et al. (2005) \\
\hline WC03 & Soybean & 41.98381 & -93.75497 & & & $\begin{array}{l}1.26 \\
(0.68)\end{array}$ & $\begin{array}{c}2.13 \\
(0.45)\end{array}$ & \\
\hline WC161 & Soybean & 41.93414 & -93.66270 & & & $\begin{array}{c}0.89 \\
(0.18)\end{array}$ & $\begin{array}{l}2.11 \\
(0.51)\end{array}$ & \\
\hline WC24 & Corn & 41.99291 & -93.52858 & & & $\begin{array}{l}3.45 \\
(0.73)\end{array}$ & $\begin{array}{l}1.99 \\
(0.29)\end{array}$ & \\
\hline WC25 & Corn & 41.94227 & -93.53937 & & & $\begin{array}{l}1.34 \\
(0.09)\end{array}$ & $\begin{array}{l}2.03 \\
(0.45)\end{array}$ & \\
\hline WC33 & Corn & 41.97534 & -93.64431 & & & $\begin{array}{l}2.52 \\
(0.70)\end{array}$ & $\begin{array}{l}2.08 \\
(0.34)\end{array}$ & \\
\hline Bushland & & 35.19472 & -102.05694 & & & & & \\
\hline ALF & Alfalfa & & & 1999 & $100-276$ & $\begin{array}{c}2.44 \\
(1.02)\end{array}$ & $\begin{array}{l}1.60 \\
(0.74)\end{array}$ & Tolk et al. (2006) \\
\hline SOR & Sorghum & & & 1997 & $163-271$ & $\begin{array}{l}1.90 \\
(1.10)\end{array}$ & $\begin{array}{l}2.70 \\
(0.94)\end{array}$ & \\
\hline WHT & Wheat & & & 1989-90 & $288-158$ & $\begin{array}{l}1.01 \\
(1.04)\end{array}$ & $\begin{array}{l}1.75 \\
(0.86)\end{array}$ & Howell et al. (1995b) \\
\hline $\mathrm{CRN}$ & Corn & & & 1999 & $167-288$ & $\begin{array}{c}2.70 \\
(1.39)\end{array}$ & $\begin{array}{l}1.99 \\
(0.65)\end{array}$ & Howell et al. (1997) \\
\hline Maricopa & Cotton & 33.08 & -111.98 & 1987 & $162-165$ & $\begin{array}{c}0.40 \\
(0.00)\end{array}$ & $\begin{array}{c}5.56 \\
(0.62)\end{array}$ & $\begin{array}{l}\text { Kustas and Norman } \\
\text { (1999) }\end{array}$ \\
\hline \multicolumn{9}{|l|}{ Natural vegetation } \\
\hline Audubon & & 31.59073 & -110.51038 & & & & & $\begin{array}{l}\text { Wilson and Meyers } \\
\text { (2007) }\end{array}$ \\
\hline AUD02 & & & & 2002 & $158-270$ & $\begin{array}{c}0.49 \\
(0.03)\end{array}$ & $\begin{array}{c}4.31 \\
(0.54)\end{array}$ & \\
\hline AUD04 & & & & 2004 & $100-170$ & $\begin{array}{c}0.17 \\
(0.06)\end{array}$ & $\begin{array}{c}3.38 \\
(0.76)\end{array}$ & \\
\hline Monsoon '90 & & & & 1990 & $210-222$ & & & $\begin{array}{l}\text { Kustas and Goodrich } \\
\text { (1994) }\end{array}$ \\
\hline Kendall & Grassland & 31.7375 & -109.94167 & & & $\begin{array}{c}0.71 \\
(0.00)\end{array}$ & $\begin{array}{l}1.83 \\
(0.58)\end{array}$ & \\
\hline Lucky Hills & Shrubland & 31.74083 & -110.04806 & & & $\begin{array}{c}0.57 \\
(0.00)\end{array}$ & $\begin{array}{c}2.72 \\
(0.78)\end{array}$ & \\
\hline SGP97 & & 35.557 & -98.017 & 1997 & $176-195$ & & & Norman et al. (2000) \\
\hline ER01 & Grassland & & & & & $\begin{array}{c}4.20 \\
(0.00)\end{array}$ & $\begin{array}{c}2.48 \\
(0.32)\end{array}$ & \\
\hline ER05 & Grassland & & & & & $\begin{array}{c}2.60 \\
(0.00)\end{array}$ & $\begin{array}{l}2.20 \\
0.53\end{array}$ & \\
\hline SMEX04 & & & & 2004 & $160-242$ & & & Li et al. 2008 \\
\hline Kendall & Grassland & 31.7375 & -109.94167 & & & $\begin{array}{c}0.39 \\
(0.15)\end{array}$ & $\begin{array}{c}2.89 \\
(0.93)\end{array}$ & \\
\hline Lucky Hills & Shrubland & 31.74083 & -110.04806 & & & $\begin{array}{c}0.38 \\
(0.13)\end{array}$ & $\begin{array}{c}3.23 \\
(1.02)\end{array}$ & \\
\hline Goodwin Creek & Grassland & 34.2547 & -89.8735 & 2003 & $121-228$ & $\begin{array}{l}3.27 \\
(0.50)\end{array}$ & $\begin{array}{l}2.51 \\
(0.54)\end{array}$ & $\begin{array}{l}\text { Wilson and Meyers } \\
\text { (2001) }\end{array}$ \\
\hline Fort Peck & Grassland & 48.3077 & -105.1019 & 2003 & 121-198 & $\begin{array}{c}2.37 \\
(0.79)\end{array}$ & $\begin{array}{c}2.06 \\
(1.17)\end{array}$ & $\begin{array}{l}\text { Wilson and Meyers } \\
\text { (2007) }\end{array}$ \\
\hline
\end{tabular}


(Li et al. 2008), SMEX02 (Anderson et al. 2005), and SGP97 (Norman et al. 2000), LAI data were acquired with LAI-2000 plant canopy analyzer (LICOR Inc.; Company and trade names are given for the benefit of the reader and imply no endorsement of the product by the USDA-ARS). During Monsoon '90, LAI was estimated using the line-intercept transect method (Canfield 1941) as detailed by (Weltz et al. 1994). LAI data from Maricopa were estimated by agronomic measurements described by Kustas et al. (1989) and Kustas (1990). The LAI estimates from the Bushland sites were obtained by descriptive plant sampling (1.5 $\mathrm{m}^{2}$ samples) in the 5-ha fields surrounding each lysimeter. In Audubon, Goodwin Creek, and Fort Peck, LAI was estimated from onsite normalized difference vegetation index (NDVI) observations (Wilson and Meyers 2007). For all sites, linear interpolation was used to estimate LAI between measurement dates.

For many sites, with the exception of OPE3, Maricopa, Audubon, Goodwin Creek, and Fort Peck, data from multiple flux towers (multiple lysimeters in Bushland) were used, and each flux tower was considered as a separate dataset. For sites with multiple years of flux acquisition, each year was considered as a distinct "flux site dataset" in the analysis. In total, 21 different flux sites were included in the study (see Table 1).

Half-hourly data at midday (1000-1400 local time) were analyzed, corresponding with periods of peak flux and typical times of daytime satellite data acquisition when the TSM is generally applied. Data were further screened to exclude cloudy conditions, as suggested by Black (1979) and Flint and Childs (1991), because under such conditions, even relatively dry soils can supply enough water to meet potential evapotranspiration.

\section{b. Data analysis}

\section{1) SCHEME FOR OPTIMIZING $\alpha_{C}$}

Direct and reliable measurements of vegetation and soil components of the surface energy balance are very difficult to obtain at canopy and field scale. Therefore, an approach was employed to estimate optimal values of $\alpha_{c}$ using the representation of flux partitioning inherent in the TSM. The optimization scheme determined the optimal $\alpha_{c}$ for each data point by iteratively running the TSM over a range in initial $\alpha_{c}$ values, varying between 0.5 and 2.5 in increments of 0.1 . For each time step at each flux site, the TSM was executed 21 times with the various $\alpha_{c}$ input values; after each execution, the modeled $\lambda E$ was compared to the measured flux. The optimal $\alpha_{c}$ was defined as the $\alpha_{c}$ value obtained from the TSM computation that resulted in the minimal error with the $\lambda E$ measurements. In addition, a bulk observed value of $\alpha$ was computed from the flux measurements using Eq. (12).

An alternative approach would have been to optimize $\alpha_{c}$ on average over the course of each day. Although this would reduce noise in the derived values of optimal $\alpha_{c}$ (in comparison with the hourly optimization employed here), it would significantly reduce the range in VPD represented in the dataset, concealing the high-VPD responses discussed later.

\section{2) INDEPENDENT VARIABLES AND DATA BINNING}

To emphasize trends in $\alpha_{c}$ and $\alpha_{\text {bulk }}$ with varying environmental factors, the resulting dataset for each flux site was averaged over bins in LAI and VPD. LAI and VPD were selected as driving variables for investigation because both potentially affect $\alpha_{\text {bulk }}$ but are independent of the Priestley-Taylor formulation [cf. Eq. (12)]. Note that soil moisture content was not measured at all sites, and therefore it could not be used as an independent variable in this study.

Data were binned into LAI ranges in increments of 1 (0-1, 1-2 . . 4-5). Within each bin, averages, standard deviations (STD), and standard errors $(\mathrm{SE}=\mathrm{STD} / \sqrt{n})$ in LAI, $\alpha_{c}$, and $\alpha_{\text {bulk }}$ were computed. In the same way, data were binned into VPD ranges in 1-kPa increments. The standard errors were computed to account for differing number of observations available for the various sites in the different bins. Linear regressions describing trends in $\alpha_{c}$ and $\alpha_{\text {bulk }}$ versus LAI and VPD were weighted by the standard errors for each binned data point (Bevington 1969).

In this study, data binning was required for trend analysis to suppress noise in optimized $\alpha$ while maintaining a wide range in the driving variables, VPD and LAI. Noise in the hourly optimized $\alpha$ values reflect uncertainties in the observations, enhanced by the variety of observational methods employed in these various studies, and the fact that these experiments were not originally designed to specifically address the topic of this study. Potentially, most problematic are the LAI and surface radiometric temperature data-key inputs to the TSM in terms of model sensitivity. An additional and significant source of uncertainty is the measurement of latent heat flux from the various micrometeorological methods and issues related to forcing energy balance closure (e.g., Twine et al. 2000). Without binning, the primary trends discussed here are obscured.

In Fig. 2 the range in LAI and VPD sampled by the observational dataset used in the current study is illustrated. Each point represents the mean LAI for the corresponding 1-unit increments described earlier and the corresponding mean VPD value. The bars represent the STD values in LAI and VPD. Several sites, where 


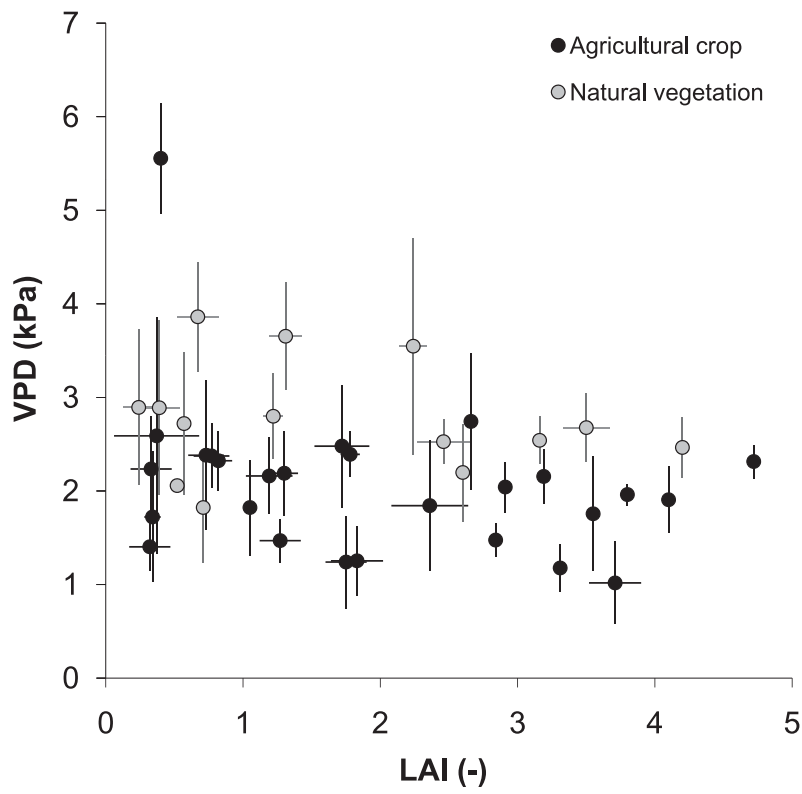

FIG. 2. A comparison of site average LAI using the binning criteria for LAI described in the text vs VPD along with the standard deviations.

the data used were collected during multiple years and/ or the data cover seasonal growth cycle, will have more than one LAI/VPD data point. Note that this study did not include data from sites with both high LAI and high VPD. In nature, such conditions are not likely to exist, because high VPD usually represents dry conditions where natural vegetation tends to be sparse. Sites with both high LAI and persistently high VPD are typically found only in small riparian areas, where micrometeorological measurements are difficult (or impossible) to conduct, or where mature crops are being artificially irrigated. In the current study, high VPD values (greater than $3 \mathrm{kPa}$ ) were only measured in sites with $\mathrm{LAI}<0.5$ (most with natural vegetation).

\section{Results and discussion}

\section{a. Effect of LAI on $\alpha$}

The bulk Priestley-Taylor coefficient does not consider the effect of the fractional vegetation cover on the soil-canopy partitioning of latent heat flux, yet this is the form in which the PT method is typically applied (e.g., Kustas et al. 1996). Figure 3a shows a set of points representing the distribution of observed $\alpha_{\text {bulk }}$ (derived directly from the flux measurements) versus the observed LAI for the combined set of flux sites. Each point represents an average for each flux site in the respective LAI bin, with $X$-axis "error bars" representing the STD of LAI (to indicate the LAI variability within each LAI bin) and $Y$-axis error bars representing the $\mathrm{SE}$ in $\alpha_{\mathrm{bulk}}$ (to normalize the standard deviation by the number of observations), which tends to be quite small. Also illustrated in Fig. 3a is the theoretical dependency of $\alpha_{\text {bulk }}$ on LAI as described by a set of analytical curves, computed using Eq. (14). These curves assume four different surface soil moisture conditions, as represented by the different values of $\alpha_{s}$. A value of $\alpha_{s}=1.3$ represents a wet bare soil surface, whereas $\alpha_{s}=0$ represents a completely dry soil surface (i.e., no evaporation from the soil), and $\alpha_{s}=0.5$ and 1.0, represent intermediate conditions. The effect of vegetation cover on $\alpha_{s}$ at nonzero LAI for the wet soil case (energy-limited case) was accounted for using Eq. (7) with $\tau_{0}=0.3$ and $\beta=$ 0.5 . For the other cases where $\alpha_{s} \leq 1, \alpha_{s}$ was assumed to be constant, which is a reasonable assumption when soil evaporation reaches stage two drying (Hillel 1971). Four of the curves use $\alpha_{c}=1.3$, assuming the vegetation is transpiring at the potential rate (unstressed). A fifth curve represents a dry soil surface $\left(\alpha_{s}=0\right)$ and $\alpha_{c}$ of 0.9 ,
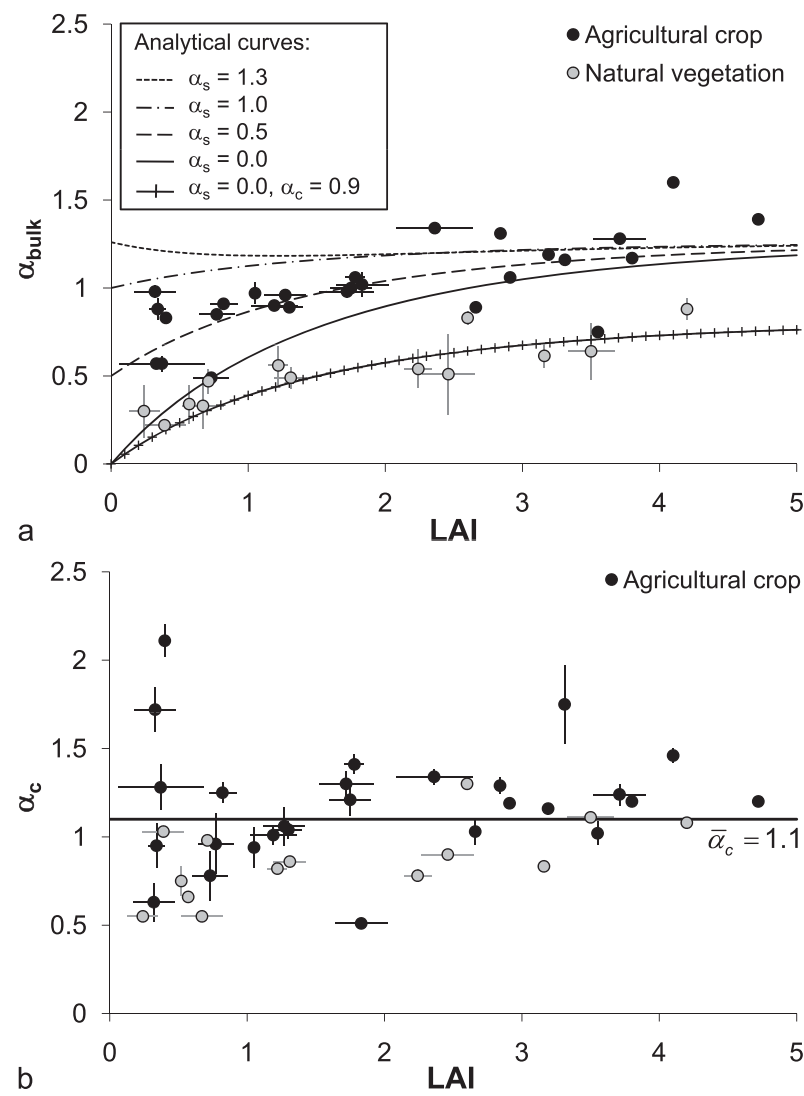

FIG. 3. The dependency of (a) $\alpha_{\text {bulk }}$ and (b) $\alpha_{c}$ on LAI. The analytical curves in (a) were derived by Eq. (14) for four different states of the soil, gradually changing from completely wet $\left(\alpha_{s}=1.3\right)$ to completely dry $\left(\alpha_{s}=0\right)$. The line in (b) represents the average $\alpha_{c}$ $(\approx 1.1)$ for the combined agricultural crops and natural vegetation datasets. 
which is the average optimized $\alpha_{c}$ value found for the natural vegetation dataset (see later). Clearly, the drier the soil, the stronger the effect of LAI on the value of $\alpha_{\text {bulk }}$, especially for LAI $<2$.

In comparing the analytical curves of $\alpha_{\text {bulk }}$ with the data points in Fig. 3a, most of the agricultural crop data points at low LAI are clustered around the unstressed canopy curves with $\alpha_{s}=0.5$ and 1.0, indicating intermediate surface soil moisture conditions at these sites (at high LAI, the curves are virtually indistinguishable). The $\alpha_{\text {bulk }}$ values for the majority of the sites with natural vegetation at higher cover (i.e., LAI $>2$ ) are clustered around the curve representing dry soil and vegetation transpiring at less than the potential rate. These findings agree well with the fact that agricultural crops tend to be grown in areas with adequate moisture achieved either by natural rainfall or by irrigation, whereas the water supply for natural vegetation is largely dependent on precipitation, which can be highly variable in space and time and is often inadequate to sustain potential ET.

Figure $3 \mathrm{~b}$ shows the mean final $\alpha_{c}$ for each LAI bin, as derived by the TSM optimization scheme. In contrast to $\alpha_{\text {bulk }}$, which showed dependency on LAI $(p<0.01), \alpha_{c}$ in this dataset is independent of LAI $(p>0.05)$. The large scatter in the optimal $\alpha_{c}$ at low LAI is attributed to the fact that $\alpha_{c}$ is not well constrained in the TSM optimization procedure using flux data over sparse vegetation. Under low vegetation cover conditions, $\mathrm{Rn}_{c}$ is relatively small, thus large changes in $\alpha_{c}$ are required to effect a significant change in $\lambda E$. However, in these cases, the contribution of canopy transpiration to the overall latent heat flux is small, and errors in computations of the transpiration flux will not induce large errors to the overall flux estimates.

For the agricultural crop dataset used in this study, the average value of optimal $\alpha_{c}$ was 1.2, close to the standard value of $\alpha_{\text {bulk }}=1.3$ that is commonly used in most bulk applications of the Priestley-Taylor approximation. This suggests that in most cases, the agricultural crops studied here were not under stress and were transpiring at close to the potential rate. The average optimal $\alpha_{c}$ value obtained for the natural vegetation dataset was 0.9. This lower value may be because most of the natural vegetation sites studied here were located in semiarid and subhumid climates, where vegetation growth is often water limited. Under such conditions, natural vegetation can adapt to frequent moisture deficits by controlling the rate of transpiration. Consequently, a lower value of $\alpha_{c}$ would be expected for these natural vegetation sites, unless sufficient root-zone moisture is always available (e.g., Stannard 1993). The average value of optimal $\alpha_{c}$ for the combined dataset (including both crops and natural vegetation) is 1.1 .

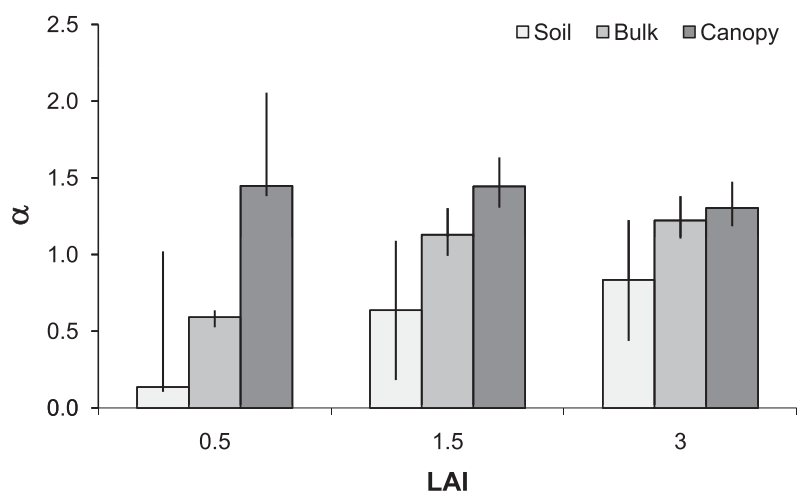

FIG. 4. The dependency of $\alpha_{c}, \alpha_{s}$, and $\alpha_{\text {bulk }}$ on LAI, as computed by the Cupid model for the Monsoon ' 90 dataset for unstressed vegetation. The error bars represent the minimum and maximum measured coefficients of each column.

The general response of $\alpha_{\text {bulk }}$ and $\alpha_{c}$ to LAI depicted in Figs. $3 \mathrm{a}$ and $3 \mathrm{~b}$ was also reproduced with a multilayer soilplant-atmosphere model, Cupid. Detailed descriptions of Cupid can be found in Norman and Campbell (1983), Norman and Arkebauer (1991), and Kustas et al. (2004). In brief, Cupid computes both radiative and turbulent exchanges across the soil-canopy-air interface while considering a wide variety of physiological and environmental processes simultaneously.

Kustas et al. $(2004,2007)$ describe a numerical experiment in which the Cupid model was first validated with the Monsoon '90 flux dataset, and then a set of hypothetical simulations was performed assuming a range of soil moisture and LAI conditions. Figure 4 shows mean values of $\alpha_{c}, \alpha_{s}$ and $\alpha_{\text {bulk }}$ derived from Cupid simulations of $\lambda E_{c}, \lambda E_{s}$, and $\lambda E$ using Eqs. (3), (11), and (12), respectively, assuming unstressed canopy conditions. Both $\alpha_{s}$ and $\alpha_{\text {bulk }}$ increase with increasing LAI, whereas $\alpha_{c}$ remains relatively constant (see also Kustas and Anderson 2009). The Cupid-derived average value of $\alpha_{c}$ of $\sim 1.4$ is slightly higher than 1.26 and reflects the fact that the unstressed simulations were run using local meteorological forcing under arid (advective) conditions (see Kustas et al. 2004). The fact that the detailed Cupid model reproduces the PT coefficient behavior observed with the simple TSM optimization scheme provides further evidence that $\alpha_{c}$ will be relatively conservative with LAI when the canopy is unstressed.

\section{b. Effect of VPD on $\alpha$}

\section{1) Agricultural CROPS}

The dependency of $\alpha_{c}$ and $\alpha_{\text {bulk }}$ on VPD for flux sites with agricultural crops is illustrated in Figs. 5a and 5b, respectively. As in Fig. 3, each point represents an average 

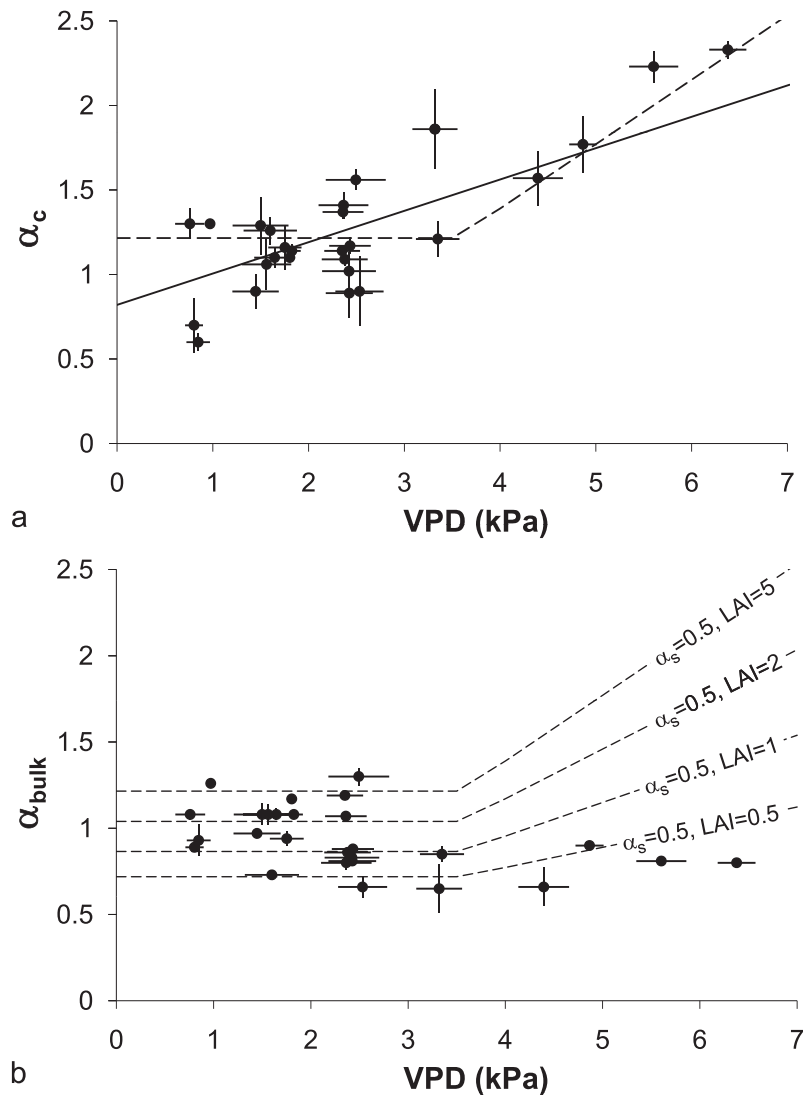

FIG. 5. The dependency of (a) $\alpha_{c}$ and (b) $\alpha_{\text {bulk }}$ on VPD for agricultural crops. In (a), the weighted regression line is represented by the solid line, whereas the dashed line is a piecewise linear fit of the assumed behavior of $\alpha_{c}$ for agricultural crops. The piecewise linear curves in (b) were generated using the analytical expression for $\alpha_{\text {bulk }}$, Eq. (14), in which $\alpha_{c}$ was taken as a function of VPD from the dashed line in (a), $\alpha_{s}$ was assumed constant and given a value of 0.5 , and LAI was assigned values of $0.5,1,2$, and 5 (see text).

for each site in the respective VPD bin, with $X$-axis error bars representing the STD of VPD and $Y$-axis error bars representing the $\mathrm{SE}$ in $\alpha$. The trend line (solid line) in Fig. 5a is derived from a statistically weighted linear regression $\left(r^{2}=0.68\right)$ and indicates a dependency of $\alpha_{c}$ on VPD. From a modeling standpoint, however, significant improvement in TSM latent heat estimates resulting from replacing the nominal value of $\alpha_{c}=1.3$ with the optimal $\alpha_{c}$ is obtained only under the high VPD range, as detailed in section $4 \mathrm{c}$ below. This suggests that a modification to $\alpha_{c}$ as utilized in the TSM for agricultural crops is required only at high VPD, as indicated by the piecewise linear relationship (i.e., dashed line) in Fig. 6a. Additional data, particularly collected under strong advective conditions and high VPD, will be required to determine a robust quantitative relationship between $\alpha_{c}$ and VPD for use in the TSM.
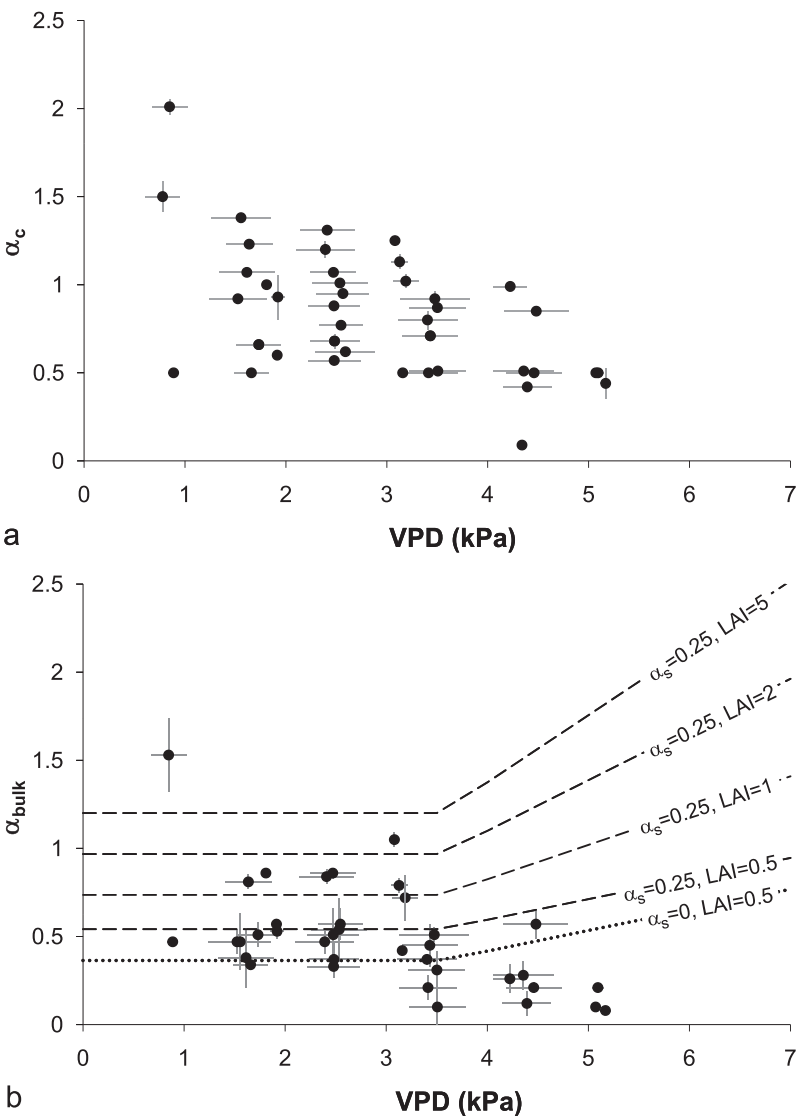

FIG. 6. The dependency of (a) $\alpha_{c}$ and (b) $\alpha_{\text {bulk }}$ on VPD for the natural vegetation. In (b), the solid line represents a weighted regression line. The dashed lines represent the analytical expression for $\alpha_{\text {bulk }}$, Eq. (14), in which $\alpha_{c}$ was taken as a function of VPD from the dashed line in Fig. 3a, $\alpha_{s}$ was assumed constant and given a value of 0.25 , based on the $\alpha_{\text {bulk }}$ values shown in Fig. 3, and LAI was assigned values of $0.5,1,2$, and 5 . The dotted line is similar to the dashed lines for the case of $\alpha_{s}=0$ and LAI $=0.5$.

Interestingly, $\alpha_{\text {bulk }}$ in Fig. 5b shows little dependency on VPD, with the statistically weighted linear regression (not shown) yielding a slope not significantly different than $0(p>0.05)$. This should not be interpreted, however, as an indication that $\alpha_{\text {bulk }}$ is conservative over this wide range in VPD. As mentioned in section $3 b(2)$, the flux dataset used here did not include data from sites with both high LAI and high VPD (Fig. 2), as might be encountered in smaller irrigated agricultural systems in the western United States. For well-watered agricultural crops, $\alpha_{\text {bulk }}$ is expected to behave similarly to $\alpha_{c}$ in Fig. 5a (i.e., increasing at high VPD). This is represented by the piecewise linear curves in Fig. $5 \mathrm{~b}$ derived from the analytical model for $\alpha_{\text {bulk }}$ in Eq. (14), for a range of LAI cases $(5,2,1$, and 0.5$)$, with $\alpha_{s}=0.5$ and $\alpha_{c}$ from Fig. 5a. If the dataset contained data from mature irrigated crops in arid climates, then the upper 
curves would be populated. The trends at the higher LAI values represent a theoretical upper bound in $\alpha_{\text {bulk }}$ because sheltering effects of dense vegetation are likely to cause dampening of the $\alpha_{c}$ response to increasing VPD, analogous to the effects on $\alpha_{s}$ described by Tanner and Jury (1976). These curves reveal how the increase in canopy transpiration but decrease in soil evaporation can cancel out under low canopy cover conditions, such that a relatively small change in the overall $\alpha_{\text {bulk }}$ is computed.

\section{2) NATURAL VegetATiON}

For the natural vegetation sites, both $\alpha_{c}$ (Fig. 6a) and $\alpha_{\text {bulk }}$ (Fig. 6b) appear to decrease with increasing VPD, although the scatter is large. The response of $\alpha_{c}$ to VPD may relate to physiological characteristics of natural vegetation growing in arid and semiarid environments. Although an increase in VPD enhances transpiration by producing stronger humidity gradient between the leaf and the atmosphere, it also initiates a negative feedback on stomatal conductance, which leads to a reduction in transpiration (Baldocchi and Xu 2007). Different adaptation mechanisms in natural vegetation lead to a stronger response of stomatal resistance to high VPD to preserve water (e.g., Baldocchi and Xu 2007; Galmes et al. 2007), causing a decrease in transpiration and thus a decrease in $\alpha_{c}$.

The decrease in $\alpha_{\text {bulk }}$ with VPD is in part due to the behavior of $\alpha_{c}$, but it also reflects the dependence of $\alpha_{s}$ on VPD, which is expected to be significant in rain-fed systems. High VPD will induce high soil evaporation rates and a rapid decrease in soil moisture, moving quickly from the first stage to the second stage of evaporation (Hillel 1971). The decrease in soil evaporation affects the overall decrease in latent heat flux, reflected in the decrease in $\alpha_{\text {bulk }}$ with VPD. The lowest group of points, in the VPD range between 3 and $6 \mathrm{kPa}$, falling below the $\alpha_{\text {bulk }}$ curve with $\alpha_{s}=0$ indicates that both the surface and profile soil moisture conditions are likely affecting the overall decrease in $\alpha_{\text {bulk. }}$. This is in contrast to the agricultural crops, which are likely to continue transpiring at the potential rate up to high values of VPD as long as ample water exists, as illustrated by the $\alpha_{\text {bulk }}$ curves (dashed lines) in Fig. 6b, derived from analysis of the $\alpha$-VPD relationship for the agricultural crops.

\section{c. Errors in TSM using $\alpha_{c}=1.3$}

For operational applications of the TSM (e.g., Anderson et al. 2007a,b), it is important to understand the errors in $\lambda E$ incurred by using the conventional initialization value of $\alpha_{c}=1.3$ for various land use and climatic conditions. In Fig. 7, the mean-absolute-error (MAE) statistic be-

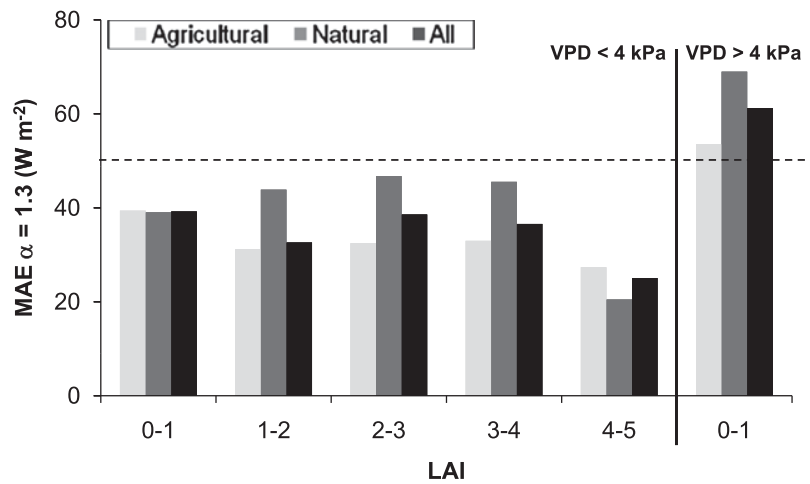

FIG. 7. Values of MAE in $\lambda E$ resulting from comparing model results with measurements when applying the conventional $\alpha_{c}=$ 1.3. The dotted line represents typical model errors obtained from other studies evaluating the performance of remote sensing-based energy balance models (Kalma et al. 2008; Kustas and Norman 2000b).

tween modeled and measured $\lambda E$ recommended by Willmott and Matsurura (2005) is used to quantify the performance of the TSM as applied to the agricultural and natural vegetation datasets, segregated by VPD (above and below $4 \mathrm{kPa}$ ) and by LAI bins. For each case, the TSM was initialized with $\alpha_{c}=1.3$, and the model was allowed to downregulate the PT coefficient in response to perceived canopy stress, as per the standard mode of model operation.

For the agricultural vegetation dataset under low-tomoderate atmospheric demand (VPD $<4 \mathrm{kPa}), \mathrm{MAE}$ values of $25 \mathrm{~W} \mathrm{~m}^{-2}$ are obtained on average over all LAI bins using $\alpha_{c}=1.3$, whereas the natural vegetation sites yielded a higher average error of $38 \mathrm{~W} \mathrm{~m}^{-2}$. If a lower value of $\alpha_{c}=1.0$ is used to initialize runs for the natural vegetation sites, as suggested by optimization results from section $4 \mathrm{a}$, then this error reduces to $24 \mathrm{~W} \mathrm{~m}^{-2}$. In either case, the errors accrued by using a fixed nominal value of $\alpha_{c}$ are comparable or superior to modelmeasurement errors encountered in many other studies applying remote sensing-based energy balance methods (Kalma et al. 2008; Kustas and Norman 2000b), which are typically on the order of $50 \mathrm{~W} \mathrm{~m}^{-2}$. Note that errors using $\alpha_{c}=1.3$ tend to decrease with increasing LAI.

Under high VPD conditions, the choice of nominal input $\alpha_{c}$ is more critical for obtaining good flux estimates from the TSM over both agricultural crops and natural vegetation. For these cases, using an input value of $\alpha_{c}=$ 1.3 produces MAE values of 54 and $67 \mathrm{~W} \mathrm{~m}^{-2}$ for agricultural and natural vegetation datasets, respectivelysomewhat higher than the $50 \mathrm{~W} \mathrm{~m}^{-2}$ errors typically reported for surface energy balance. This suggests that a VPD-dependent function of $\alpha_{c}$ may be beneficial in reducing model errors under conditions of very high 
atmospheric demand. For natural vegetation, a lower value of input $\alpha_{c}$ may be warranted, reflecting the relatively conservative water-use tendencies of undomesticated plants. Additional data under high VPD conditions $(>4 \mathrm{kPa})$ is required to thoroughly evaluate this hypothesis.

\section{Conclusions}

This study examined the utility of the PT approach in providing an initial value for canopy transpiration, required for solving the surface energy balance using the TSM scheme. In the TSM, the PT approximation is applied only to the canopy component of the system latent heat flux, reflecting the ability of the vegetation to transpire, and hence $\alpha_{c}$ is expected to be relatively conservative with respect to changes in LAI. The PT coefficient for the bulk (soil + canopy) system $\alpha_{\text {bulk }}$ shows a different behavior, typically decreasing at low vegetation cover, density, or LAI with the increasing influence of soil evaporation component of ET.

For agricultural crops under low-to-moderate VPD conditions $(0<$ VPD $<4)$, initializing the TSM with a constant $\alpha_{c}=1.3$ did not significantly degrade model performance in estimating $\lambda E$ compared to using the optimal $\alpha_{c}$ (Fig. 7). For the natural vegetation, data using $\alpha_{c}=1.3$ yielded somewhat larger errors, which might be reduced if the TSM were initialized with a lower value of $\alpha_{c}$. Nevertheless, in either case, the model errors for runs using a nominal value of $\alpha_{c}=1.3$ are comparable to model-measurement errors encountered in many other studies applying remote sensing-based energy balance methods (Kalma et al. 2008). This is a benefit, because in practice, the optimal value of $\alpha_{c}$ will not be known a priori.

On the other hand, under strong advective conditions with high VPD $(>4 \mathrm{kPa})$ and at sites with sufficient available soil moisture (in this study represented only by agricultural crops), the estimated value of $\alpha_{c}$ increased significantly with VPD (cf. Fig. 5a). Under such conditions, agricultural crops will increase transpiration to meet atmospheric demand as long as an ample root-zone water supply exists. For these cases, significantly larger errors in modeled $\lambda E$ resulted for both vegetation types (particularly agricultural crops) when using a nominal $\alpha_{c}=1.3$ as compared to the optimal $\alpha_{c}$ (Fig. 7). For sites with natural vegetation, $\alpha_{c}$ did not increase with increasing VPD (Fig. 6a), as was observed for crop sites (Fig. 5a). This may reflect limitations in available soil moisture at these sites, which tended to be in semiarid and subhumid climates, and a greater tendency for undomesticated vegetation to reduce water loss/transpiration under high VPD conditions.
Overall, the findings suggest that, except under very high VPD conditions, initialization of the TSM with the conventional value of $\alpha_{c}=1.3$ does not significantly degrade the model performance, especially for agricultural crops. This analysis provides some insight as to why the PT approach, initially developed for regional estimates of potential evapotranspiration, can be used successfully in the TSM scheme, yielding reliable heat flux estimates over typical agricultural crops, as well as grassland- and shrubland-type natural vegetation. Future work will focus on evaluating the PT approach under very high VPD conditions and for deciduous and coniferous forests.

Acknowledgments. This research was supported by Vaadia-BARD Postdoctoral Fellowship Award FI-3712005 from BARD, the United States-Israel Binational Agricultural Research and Development Fund.

\section{REFERENCES}

Anderson, M. C., J. M. Norman, W. P. Kustas, F. Li, J. H. Prueger, and J. M. Mecikalski, 2005: Effects of vegetation clumping on two-source model estimates of surface energy fluxes from an agricultural landscape during SMACEX. J. Hydrometeor., 6, 892-909.

,-- J. R. Mecikalski, J. A. Otkin, and W. P. Kustas, 2007a: A climatological study of evapotranspiration and moisture stress across the continental United States based on thermal remote sensing: 1. Model formulation. J. Geophys.Res., 112, D10117, doi:10.1029/2006JD007506.

,,,,---- and,$- 2007 \mathrm{~b}$ : A climatological study of evapotranspiration and moisture stress across the continental United States based on thermal remote sensing: 2. Surface moisture climatology. J. Geophys. Res., 112, D1112, doi:10.1029/2006JD007507.

Baldocchi, D., 1994: A comparative study of mass and energy exchange over a closed C3 (wheat) and an open C4 (corn) canopy: I. The partitioning of available energy into latent and sensible heat exchange. Agric. For. Meteor., 67, 191-220.

— nean oak woodlands - The supply of moisture in the soil, physiological control by plants or the demand by the atmosphere? Adv. Water Resour., 30, 2113-2122.

_ C. A. Vogel, and B. Hall, 1997: Seasonal variation of energy and water vapor exchange rates above and below a boreal jack pine forest canopy. J. Geophys. Res., 102, 28 939-28 951.

Bevington, P. R., 1969: Data Reduction and Error Analysis for the Physical Sciences. McGraw-Hill, 336 pp.

Black, T. A., 1979: Evapotranspiration from Douglas fir stands exposed to soil water deficits. Water Resour. Res., 15, 164-170.

Campbell, G. S., and J. M. Norman, 1998: An Introduction to Environmental Biophysics. Springer-Verlag, $312 \mathrm{pp}$.

Canfield, R. H., 1941: Application of the line interception method in sampling range vegetation. J. For., 39, 388-394.

Castellvi, F., C. O. Stockle, P. J. Perez, and M. Ibanez, 2001: Comparison of methods for applying the Priestley-Taylor equation at a regional scale. Hydrol. Processes, 15, 1609-1620.

Choudhury, B. J., N. U. Ahmed, S. B. Idso, R. J. Reginato, and C. S. T. Daughtry, 1994: Relations between evaporation 
coefficients and vegetation indices studied by model simulations. Remote Sens. Environ., 50, 1-17.

De Bruin, H. A. R., 1983: A model for the Priestley-Taylor parameter $\alpha$. J. Climate Appl. Meteor., 22, 572-578.

Diaz-Espejo, A., A. Verhoef, and R. Knight, 2005: Illustration of micro-scale advection using grid-pattern mini-lysimeters. Agric. For. Meteor., 129, 39-52.

Flint, A. L., and S. W. Childs, 1991: Use of the Priestley-Taylor evaporation equation for soil water limited conditions in a small forest clearcut. Agric. For. Meteor., 56, 247-260.

François, C., 2002: The potential of directional radiometric temperatures for monitoring soil and leaf temperature and soil moisture status. Remote Sens. Environ., 80, 122-133.

French, A. N., T. J. Schmugge, W. P. Kustas, K. L. Brubaker, and J. H. Prueger, 2003: Surface energy fluxes over El Reno, Oklahoma, using high-resolution remotely sensed data. Water Resour. Res., 39, 1164, doi:10.1029/2002WR001734.

_ vanced Spaceborne Thermal Emission and Reflection radiometer (ASTER) at the Iowa 2002 SMACEX site (USA). Remote Sens. Environ., 99, 55-65.

Galmes, J., H. Medrano, and J. Flexas, 2007: Photosynthetic limitations in response to water stress and recovery in Mediterranean plants with different growth forms. New Phytol., 175, 81-93.

Hillel, D., 1971: Soil and Water: Physical Principles and Processes. Academic Press, 288 pp.

Howell, T. A., A. D. Schneider, D. A. Dusek, T. H. Marek, and J. L. Steiner, 1995a: Calibration and scale performance of Bushland weighing lysimeters. Trans. ASAE, 38, 1019-1024.

— J. L. Steiner, A. D. Schneider, and S. R. Evett, 1995b: Evapotranspiration of Irrigated Winter Wheat-Southern High Plains. Trans. ASAE, 38, 745-759.

,,,,---- and J. A. Tolk, 1997: Seasonal and Maximum Daily Evapotranspiration of Irrigated Winter Wheat, Sorghum, and Corn - Southern High Plains. Trans. ASAE, 40, 623-634.

Jury, W. A., and C. B. Tanner, 1975: Advection modification of the Priestley and Taylor evapotranspiration formula. Agron. J., 67, 840-842.

— from a row crop during incomplete cover. Agron. J., 68, 239243.

Kalma, J. D., T. R. McVicar, and M. F. McCabe, 2008: Estimating land surface evaporation: A review of methods using remotely sensed surface temperature data. Surv. Geophys., 29, 421-469.

Kustas, W. P., 1990: Estimates of evapotranspiration with a oneand two-layer model of heat transfer over partial canopy cover. J. Appl. Meteor., 29, 704-715.

— , and D. C. Goodrich, 1994: Preface. Water Resour. Res., 30, 1211-1225.

— mating turbulent fluxes using multiple angle thermal infrared observations. Water Resour. Res., 33, 1495-1508.

$\ldots$, and $—$ 1999: Evaluation of soil and vegetation heat flux predictions using a simple two-source model with radiometric temperatures for partial canopy cover. Agric. For. Meteor., 94, 13-29.

— ing directional radiometric temperature observations for sparse canopy covered surfaces. Agron. J., 92, 847-854.

$\longrightarrow$, and $-2000 \mathrm{~b}$ : Evaluating the effects of subpixel heterogeneity on pixel average fluxes. Remote Sens. Environ., 74, $327-342$.
, and M. C. Anderson, 2009: Advances in thermal infrared remote sensing for land surface modeling. Agric. For. Meteor., 149, 2071-2081. doi:10.1016/j.agrformet.2009.05.016.

B. J. Choudhury, M. S. Moran, R. D. Reginato, R. D. Jackson, L. W. Gay, and H. L. Weaver, 1989: Determination of sensible heat flux over sparse canopy using thermal infrared data. Agric. For. Meteor., 44, 197-216.

- D. I. Stannard, and K. J. Allwine, 1996: Variability in surface energy flux partitioning during Washita '92: Resulting effects on Penman-Monteith and Priestley-Taylor parameters. Agric. For. Meteor., 82, 171-193.

, J. M. Norman, T. J. Schmugge, and M. C. Anderson, 2004: Mapping surface energy fluxes with radiometric temperature. Thermal Remote Sensing in Land Surface Processes, D. A. Quattrochi and J. C. Luvall, Eds., CRC Press, 205-253.

— J J. Hatfield, and J. H. Prueger, 2005: The Soil MoistureAtmosphere Coupling Experiment (SMACEX): Background, hydrometeorological conditions, and preliminary findings. J. Hydrometeor., 6, 791-804.

— M. C. Anderson, J. M. Norman, and F. Li, 2007: Utility of radiometric aerodynamic temperature relations for heat flux estimation. Bound.-Layer Meteor., 122, 167-187.

Li, F., W. P. Kustas, J. H. Prueger, C. M. U. Neale, and T. J. Jackson, 2005: Utility of remote sensing-based twosource energy balance model under low- and high-vegetation cover conditions. J. Hydrometeor., 6, 878-891.

- - M. C. Anderson, T. J. Jackson, R. Bindlish, and J. H. Prueger, 2006: Comparing the utility of microwave and thermal remote-sensing constraints in two-source energy balance modeling over an agricultural landscape. Remote Sens. Environ., 101, 315-328.

,,,--- J. H. Prueger, and R. L. Scott, 2008: Effect of remote sensing spatial resolution on interpreting tower-based flux observations. Remote Sens. Environ., 112, 337-349.

Li, L., and Q. Yu, 2007: Quantifying the effects of advection on canopy energy budgets and water use efficiency in an irrigated wheat field in the North China Plain. Agric. Water Manage., 89, 116-122.

Monteith, J. L., 1981: Evaporation and surface temperature. Quart. J. Roy. Meteor. Soc., 107, 1-27.

Morgan, C. L. S., J. M. Norman, and B. Lowery, 2003: Estimating plant-available water across a field with an inverse yield model. Soil Sci. Soc. Amer. J., 67, 620-629.

Norman, J. M., and G. Campbell, 1983: Application of a plantenvironment model to problems in irrigation. Advances in Irrigation, D. Hillel, Ed., Academic Press, 156-188.

— ciency from leaf characteristics. Modeling Plant and Soil Systems, J. T. Ritchie and R. J. Hanks, Eds., ASA Society, 125-143.

— W. P. Kustas, and K. S. Humes, 1995: Source approach for estimating soil and vegetation energy fluxes in observations of directional radiometric surface temperature. Agric. For. Meteor., 77, 263-293.

, — - J. H. Prueger, and G. R. Diak, 2000: Surface flux estimation using radiometric temperature: A dual temperature difference method to minimize measurement error. Water Resour. Res., 36, 2263-2274.

Otterman, J., T. W. Brakke, and J. Susskind, 1992: A model for inferring canopy and underlying soil temperatures from multidirectional measurements. Bound.-Layer Meteor., 61, 81-97.

Penman, H., 1948: Natural evaporation from open water, bare soil, and grass. Proc. Roy. Soc. London, A193, 120-146. 
Pereira, A. R., 2004: The Priestley-Taylor parameter and the decoupling factor for estimating reference evapotranspiration. Agric. For. Meteor., 125, 305-313.

— S. R. Green, and N. A. Villa Nova, 2007: Sap flow, leaf area, net radiation and the Priestley-Taylor formula for irrigated orchards and isolated trees. Agric. Water Manage., 92, $48-52$.

Priestley, C. H. B., and R. J. Taylor, 1972: On the assessment of surface heat flux and evaporation using large-scale parameters. Mon. Wea. Rev., 100, 81-92.

Raupach, M. R., 2000: Equilibrium evaporation and the convective boundary layer. Bound.-Layer Meteor., 96, 107-141.

Ritchie, J. T., 1972: Model for predicting evaporation from a row crop with incomplete cover. Water Resour. Res., 8, 1204-1213.

Sanchez, J. M., W. P. Kustas, V. Caselles, and M. C. Anderson, 2008: Modelling surface energy fluxes over maize using a two-source patch model and radiometric soil and canopy temperature observations. Remote Sens. Environ., 112, 11301143.

Sauer, T. J., J. W. Singer, J. H. Prueger, T. M. DeSutter, and J. L. Hatfield, 2007: Radiation balance and evaporation partitioning in a narrow-row soybean canopy. Agric. For. Meteor., 145, 206-214.

Shuttleworth, W. J., and J. S. Wallace, 1985: Evaporation from sparse crops - An energy combination theory. Quart. J. Roy. Meteor. Soc., 111, 839-855.

, and R. J. Gurney, 1990: The theoretical relationship between foliage temperature and canopy resistance in sparse crops. Quart. J. Roy. Meteor. Soc., 116, 497-519.

Singh, B., and R. Taillefer, 1986: The effect of synoptic-scale advection on the performance of the Priestley-Taylor evaporation formula. Bound.-Layer Meteor., 36, 267-282.
Slatyer, R. O., and I. C. McIlroy, 1961: Practical microclimatology with special reference to the water factor in soil-plantatmosphere relationships. CSIRO and UNESCO, $338 \mathrm{pp.}$

Stannard, D. I., 1993: Comparison of Penman-Monteith, ShuttleworthWallace, and modified Priestley-Taylor evapotranspiration models for wildland vegetation in semiarid rangeland. Water Resour. Res., 29, 1379-1392.

, J. H. Blanford, W. P. Kustas, W. D. Nichols, S. A. Amer, T. J. Schmugge, and M. A. Weltz, 1994: Interpretation of surface flux measurements in heterogeneous terrain during the MONSOON '90 experiment. Water Resour. Res., 30, 1227-1239.

Tanner, C. B., and W. A. Jury, 1976: Estimating evaporation and transpiration from a row crop during incomplete cover. Agron. J., 68, 239-242.

Tolk, J. A., T. A. Howell, and S. R. Evett, 2006: Nighttime evapotranspiration from alfalfa and cotton in a semiarid climate. Agron. J., 98, 730-736.

Twine, T. E., and Coauthors, 2000: Correcting eddy-covariance flux underestimates over a grassland. Agric. For. Meteor., 103, 279-300.

Weltz, M. A., J. C. Ritchie, and H. D. Fox, 1994: Comparison of laser and field measurements of vegetation height and canopy cover. Water Resour. Res., 30, 1311-1320.

Willmott, C. J., and K. Matsuura, 2005: Advantages of the mean absolute error (mae) over the root mean square error (rmse) in assessing average model performance. Climate Res., 30, 79-82.

Wilson, K. B., and T. P. Meyers, 2001: The spatial variability of energy and carbon dioxide fluxes at the floor of a deciduous forest. Bound.-Layer Meteor., 98, 443-473.

Wilson, T. B., and T. P. Meyers, 2007: Determining vegetation indices from solar and photosynthetically active radiation fluxes. Agric. For. Meteor., 144, 160-179. 